\title{
Tipos e Gêneros Textuais: Modos de Leitura e de Escrita
}

Edleise MENDES

(UFBa)

[...] todo texto é uma máquina preguiçosa pedindo ao leitor que faça uma parte do seu trabalho.

(ECO, 1994, p. 9)

Resumo: Pretende-se, neste artigo, refletir sobre as diferenças entre as noções de tipos e gêneros textuais e sua influência no desenvolvimento da leitura e da escrita em língua materna, em diferentes níveis de escolarização. Com isso, busca-se contribuir para minimizar a confusão conceitual que cerca o tema, a qual tem produzido reflexos negativos sobre os modos como textos e discursos são trabalhados em sala de aula.

Palavras-chave: gêneros textuais; leitura; escrita

Abstract: The aim of this article is to reflect about the differences among notions of textual types and text genres and their influences upon the development of writing and reading in mother tongue, on different levels of education. Thus, we ought to contribute to minimize the conceptual confusion driven by this issue which has brought negative reflexes on the way that texts and discourses are dealt with in the classrooms.

Keywords: text genres; reading; writing

\section{Leitura e escrita como práticas sociais}

Todos nós, ao longo de nossas vidas, construímos diferentes histórias como leitores e escritores. Alguns, por terem a experiência de viver em ambientes de leitores e, conseqüentemente, vivenciarem práticas de letramento, fazem da leitura e da escrita companheiras cotidianas. Infelizmente, nem todos têm essa oportunidade. Grande parte dos que alcançaram, pelo menos, um grau mediano de instrução, e, ainda, 
muitos dos que fazem parte do seleto grupo dos sujeitos considerados cultos, têm pouco ou nenhum contato com a leitura e a escrita de modo crítico, autônomo e criativo. Isto significa fazer uso da linguagem em toda sua potencialidade, produzindo, compreendendo e fazendo circular textos, discursos e sentidos em diferentes níveis de complexidade, graus de formalidade e de adequação contextual.

Ler e escrever, por exemplo, para a maioria dos jovens que ingressam em um curso de nível superior, funcionam como ferramentas que resolvem, em certa medida, as demandas do dia-a-dia, como responder a e-mails, redigir bilhetes curtos, decodificar documentos, cartazes, avisos etc., mesmo estando rodeados de códigos, imagens e infinitos modos de significação. Nesse momento, quando são cobrados a participar, de modo efetivo, das atividades exigidas pelo mundo acadêmico, surpreendem-se com a constatação de que se comunicar em sua própria língua é algo mais amplo do que decifrar mensagens do cotidiano. Mas qual a importância de ler e escrever, de modo competente e crítico, no mundo contemporâneo? O que significa pensar a leitura e a escrita como práticas sociais?

Essas perguntas parecem óbvias, principalmente se o nosso ponto de referência é o mundo letrado. De certo modo, aqueles que decifram os letreiros de ônibus, fazem listas de compras, lêem notícias breves no jornal e redigem bilhetes para o(a) namorado(a) não estão participando de práticas sociais de letramento? Mas isso é suficiente? Para quem? No mundo cada vez mais acelerado em que vivemos, no qual a troca de informações, em grande escala, pode ser feita por um simples toque no teclado, e no qual as exigências do mercado de trabalho exacerbam os saberes especializados, comunicar-se competentemente em nossa própria língua tem sido um diferencial.

Se aludirmos à célebre afirmação de Paulo Freire de que a leitura do mundo precede a leitura da palavra, compreendemos que o que o nosso grande educador quis nos fazer entender é que ler ultrapassa a mera capacidade de decodificar letras e relacioná-las a sons, e, ainda, ler exige do leitor-escritor um sentido voltado para as coisas do mundo e sua relação com a linguagem que nos constitui como sujeitos em nossa relação com a exterioridade, sobretudo com o outro. No entanto, analogamente, como nos lembra Yunes (2002), a leitura da palavra também condiciona a leitura do mundo. Ou melhor, os modos como 
lemos e escrevemos as palavras, condicionam os modos como percebemos o mundo. Nesse sentido,

[...] resgatar a capacidade leitora dos indivíduos significa restituirlhes a capacidade de pensar e de se expressar cada vez mais adequadamente em sua relação social, desobstruindo o processo de construção de sua cidadania que se dá pela constituição do sujeito, isto é, fortalecendo o espírito crítico. (YUNES, 2002, p. 54)

Não cabe nesse texto uma discussão sobre o papel da leitura e da escrita em nossa sociedade, nem sobre o fato de que, em muitas esferas do cotidiano, fazemos uso limitado das possibilidades comunicativas que a nossa língua oferece. Assumo, aqui, que este escrito, mais do que dirigido a acadêmicos ou leitores/escritores maduros, volta-se para aqueles que têm pouca ou nenhuma intimidade com a nossa língua em sua modalidade escrita, principalmente o grande número de jovens que ingressam no ensino superior sem ainda se darem conta disso; e para os obstinados como eu, professores ou não, que trabalham cotidianamente para desenvolver essas práticas junto aos nossos alunos e à sociedade em geral.

Este artigo, portanto, busca tecer algumas reflexões sobre os diferentes textos e formas de discurso que nos rodeiam, buscando esclarecer os conceitos de tipos textuais e gêneros textuais e como essa compreensão pode contribuir para o desenvolvimento de práticas de leitura e escrita mais efetivas e adequadas às exigências comunicativas do mundo contemporâneo.

\section{Ler e escrever: as diferentes faces do texto}

As discussões contemporâneas sobre os diferentes usos da linguagem, na perspectiva dos estudos do discurso, da pragmática ou da lingüística do texto, têm contribuído para modificar ou, pelo menos, forçar uma re-olhada nas práticas de ensino de língua materna, sobretudo no que diz respeito ao desenvolvimento da competência comunicativa, oral e escrita, do falante. Ler e escrever, por exemplo, têm sido eleitos eixos fundamentais a partir dos quais todas as atividades que compõem a unidade da aula de língua se desenvolvem, pelo menos na teoria e nas orientações fornecidas pelos Parâmetros Curriculares 
Nacionais para o Ensino de Língua Portuguesa (PCNs). No entanto, sabemos que ainda persistem, em nossas salas de aula, práticas mecânicas de leitura e produção de textos, nas quais o caráter formal e lingüístico tem supremacia sobre os sócio-comunicativos e discursivos.

O trabalho com a leitura e a escrita envolve uma gama de aspectos, cognitivos, lingüísticos e socioculturais, que precisam ser pensados e integrados nas práticas que desenvolvemos, quer como leitores e produtores de textos, quer como professores - e aqui não incluo apenas os professores de língua! Nesse sentido, para compreendermos como nos comunicamos e interagimos com o mundo à nossa volta, é necessário lançar um olhar sobre os modos como produzimos, compreendemos e fazemos circular textos em nossa vida cotidiana. Para isso, é necessário estabelecer algumas distinções importantes quanto aos conceitos de tipos e gêneros textuais, bem como a sua relação com as práticas sociais de produção e recepção de textos e discursos. Antes disso, no entanto, é importante deixar claro o que entendemos por texto e por discurso, visto que, em muitos momentos, essas duas instâncias da ação comunicativa são tomadas como sinônimas. Segundo Marcuschi (2005, p. 24), por exemplo:

Embora haja muita discussão a esse respeito, pode-se dizer que texto é uma entidade concreta realizada materialmente e corporificada em algum gênero textual. Discurso é aquilo que um texto produz ao se manifestar em alguma instância discursiva. Assim, o discurso se realiza nos textos.

O texto, portanto, é a instância formal de expressão do discurso, o modo pelo qual os sujeitos constroem sentidos e estabelecem diálogos intersubjetivos. Koch (2005a, p. 17) nos traz bastante clara essa idéia, quando considera que o texto é "o próprio lugar da interação e os interlocutores, como sujeitos ativos que - dialogicamente - nele se constroem e são construídos". E, em outro momento, Koch (2005b, p. 27) define o texto como:

[...] uma manifestação verbal constituída de elementos lingüísticos selecionados e ordenados pelos co-enunciadores, durante a atividade verbal, de modo a permitir-lhes, na interação, não apenas a depreensão de conteúdos semânticos, em decorrência da ativação de processos e 
estratégias de ordem cognitiva, como também interação (ou atuação) de acordo com práticas socioculturais.

O texto, desse modo, é a materialidade do discurso, sua forma de expressão lingüística, através da qual o sujeito constrói pontes em sua relação com o outro e com o mundo que o cerca, e se (re)vela e compartilha sentidos, saberes e experiências. Nossos alunos, portanto, produzem discursos através de textos, em textos.

Também com relação à noção de gênero, encontramos as denominações gênero textual e gênero discursivo, a depender do ponto de vista e das escolhas teóricas do autor. De modo geral, as duas têm sido tratadas como sinônimas, embora, para efeito didático e pela própria distinção entre texto e discurso tratada anteriormente, eu prefira me reportar a gênero textual, a não ser quando a referência está sendo feita a outros autores, como Bakhtin, que trabalham com a noção de gênero do discurso.

A reflexão sobre gênero textual tem sido, de certo modo, uma prática recente e produtiva no meio acadêmico contemporâneo. Entre outros motivos, ela foi desencadeada, por um lado, pelas orientações difundidas pelos PCNs para o ensino de Língua Portuguesa, como ressalta Brait (2002), e também Kleiman (2005), que destaca que a proposta dos PCNs desencadeou um movimento relevante de pesquisa que visa, entre outras coisas, "descrever uma diversidade considerável de gêneros a partir dos heterogêneos textos que os atualizam.”. Brait (2002), no entanto, observa que, embora essas orientações sugiram o ensino de língua materna a partir de gêneros discursivos, também contribuem para perpetuar a confusão terminológica entre os conceitos de gênero e tipo textual, uma vez que fundem orientações teóricas diferentes, sem uma adequada explicação do que vem a ser cada um desses conceitos e seus modos de operar nas práticas de letramento. Confusão, aliás, bastante comum nos livros didáticos de Língua Portuguesa, como nos mostra a pesquisa de Bonini (1998), e os trabalhos que venho desenvolvendo de análise de livros didáticos com alunos do curso de Licenciatura em Letras.

Por outro lado, a crescente incapacidade dos estudantes, tanto do ensino fundamental quanto do médio, de produzirem e compreenderem textos, dos mais diferentes graus de complexidade, forçou essa discussão, visto que a noção de texto na escola tem sido 
reduzida à estrutura lingüística, e não vista, como seria desejável, como resultado da ação humana de produzir sentidos através da linguagem. Os alunos ingressos nos cursos de nível superior, desse modo, trazem esse histórico de insucesso, sobretudo aqueles oriundos do sistema público de ensino.

De modo geral, aqueles que tratam de gênero, elegem Bahktin como ponto de partida - teórico russo que, no início do século, debruçou-se sobre a noção de gênero como a forma dos sujeitos produzirem sentidos através de enunciados e discursos e sua relação com os contextos sócio-históricos que os abrigam. Embora nem sempre as apropriações de seus conceitos sejam coerentes, as suas idéias representam um forte ponto de ancoragem para a compreensão do problema. Segundo as idéias de Bakhtin (2000, p. 279):

Todas as esferas da atividade humana, por mais variadas que sejam, estão sempre relacionadas com a utilização da língua. Não é de surpreender que o caráter e os modos dessa utilização sejam tão variados como as próprias esferas da atividade humana, o que não contradiz a unidade nacional de uma língua. A utilização da língua efetua-se em forma de enunciados (orais e escritos), concretos e únicos, que emanam dos integrantes duma ou doutra esfera da atividade humana. [...] Qualquer enunciado considerado isoladamente é, claro, individual, mas cada esfera de utilização da língua elabora seus tipos relativamente estáveis de enunciados, sendo isso que denominamos gêneros do discurso.

Por serem produtos da atividade humana, os gêneros do discurso são, para Bakhtin (2000, p. 301), caracterizados pela heterogeneidade, tamanha a sua riqueza, variedade e possibilidade infinita de realização: "o querer-dizer do locutor se realiza acima de tudo na escolha de um gênero do discurso". Cada esfera da atividade humana, desse modo, comporta um repertório de gêneros do discurso que se renova à medida que a esfera se desenvolve e sofre mutações. Por sua diversidade, os gêneros incluem uma variada gama de expressões, que são orientadas conforme o contexto e as intenções enunciativas do sujeito. Isto inclui os diálogos, os relatos, as cartas, as ordens, os ofícios, as declarações, as exposições científicas, os textos literários etc.; cada um desses, possibilitando a incorporação de variadas formas interrelacionadas. 
Bakhtin (2000) chama-nos a atenção para a importante questão do estudo dos textos literários que, como discutiram muitos teóricos da linguagem, sempre foi o ponto de partida quando o foco era a questão do gênero. No entanto, os gêneros literários, como observa:

[...] tanto na Antigüidade como na época contemporânea, sempre foram estudados pelo ângulo artístico-literário de sua especificidade, das distinções diferenciais intergenéricas (nos limites da literatura), e não enquanto tipos particulares de enunciados que se diferenciam de outros tipos de enunciados, com os quais contudo têm em comum a natureza verbal (lingüística).

Essa compreensão é importante na medida em que o texto literário, embora mantenha as suas especificidades quanto ao valor estético e estilístico do trabalho com a linguagem, também incorpora, em seu conjunto, uma série de gêneros inter-relacionados que, por sua natureza e características, podem aproximar-se de outros gêneros não necessariamente literários. Estudar as formas literárias como gêneros, considerando-se as especificidades de cada texto-discurso, auxilia-nos a dissolver as dicotomias tradicionais: literário x não literário, gêneros literários x gêneros jornalísticos, argumentativos etc.

A partir de Bakhtin, a noção de gêneros discursivos passou a ser ponto de partida para muitas reflexões sobre a linguagem, em diferentes perspectivas e orientações teóricas. Como formas da atividade humana de comunicar-se e interagir com o mundo, os gêneros discursivos (ou textuais), como ressalta Marcuschi (2005, p. 20), "surgem, situam-se e integram-se funcionalmente nas culturas em que se desenvolvem". Desse modo, são formas de ação social, práticas sóciohistóricas de produção de sentidos através da linguagem, as quais "caracterizam-se muito mais por suas funções comunicativas, cognitivas e institucionais do que por suas peculiaridades lingüísticas e estruturais". Isso não significa, como ele mesmo ressalta, que as propriedades formais que caracterizam os gêneros sejam desprezadas, uma vez que estas, em muitos contextos, determinam o gênero do texto e não a sua função comunicativa; assim como o suporte (ambiente) em que o texto aparece, também pode determinar o gênero que o caracteriza. 
Os gêneros textuais, por serem construtos de sujeitos culturais e, portanto, refletirem as demandas dos contextos sócio-históricos e sócio-comunicativos que os envolvem, freqüentemente se renovam e incorporam novas formas de significação, que são fruto das mudanças e exigências da sociedade em movimento. Basta-nos imaginar, por exemplo, a infinidade de novos gêneros textuais surgidos em decorrência do advento das novas tecnologias da comunicação e da informação, sobretudo o que nos proporcionou a grande "janela" da internet. Para Marcuschi (2005), desse modo, embora os gêneros possuam alto poder preditivo, porque revelam práticas de produção de sentidos compartilhadas socialmente, são também reveladores das ações humanas e, portanto, do seu poder criativo e mutável, como já nos revelava Bakhtin (2000).

A noção de gênero, tal como a vimos tratando aqui, não oferece maiores dificuldades de compreensão, sobretudo se a relacionarmos com a infinidade de textos e modos de significação, oral, escrito e visual que encontramos disponíveis no mundo à nossa volta. A questão crucial, no entanto, é estabelecer a distinção entre os significados de gênero e tipo textual, principalmente pelo emaranhado de definições e confusão terminológica que cercam os termos na literatura existente sobre o tema e, principalmente, nos manuais didáticos para o ensino de língua portuguesa e redação.

Muitos dos que discutem essa distinção partem da premissa bakhtiniana de que "a comunicação verbal só é possível por algum gênero textual", como afirma Marcuschi (2005, p. 22). Para este autor, ao lado dessa afirmação está uma concepção de língua como "forma de ação social e histórica que, ao dizer, também constitui a realidade [...]. É neste contexto que os gêneros textuais se constituem como ações sócio-discursivas para agir sobre o mundo e dizer o mundo, constituindo-o de algum modo".

A distinção, portanto, entre gênero textual e tipo textual tem em sua base a concepção de língua como instância da interação humana, a qual nos constitui e também o mundo à nossa volta. Tudo o que fazemos e dizemos através da linguagem, desse modo, é produto da ação de sujeitos que falam de um determinado lugar social, cultural e histórico. Sobre essa distinção, uma das mais relevantes é a proposta por Marcuschi (2005, p. 22), a qual integra a visão de muitos teóricos 
que se debruçaram sobre o tema. ${ }^{1}$ Segundo o autor, tipo textual caracteriza-se por:

Uma espécie de seqüência teoricamente definida pela natureza lingüistica de sua composição \{aspectos lexicais, sintáticos, tempos verbais, relações lógicas $\}$. Em geral, os tipos textuais abrangem cerca de meia dúzia de categorias conhecidas como: narração, argumentação, exposição, descrição, injunção. ${ }^{2}$

Gênero textual, por sua vez, representaria os "textos materializados que encontramos em nossa vida diária e que apresentam características sócio-comunicativas definidas por conteúdos, propriedades funcionais, estilo e composição característica".

Depreende-se dessas definições que os tipos textuais são limitados, enquanto os gêneros textuais quase que infinitos, formando um inventário aberto de possibilidades textuais-discursivas. Como exemplo de gêneros textuais, Marcuschi (2005) destaca: telefonema, sermão, cartas (e suas variantes), romance, bilhete, aula expositiva, receita, horóscopo, resenha, lista de supermercado, edital de concurso, piada, notícia jornalística etc. Para alguns autores, como Adam (apud Bonini, 2002), a noção de tipo textual é substituída por sequiencia textual, opção eleita por muitos teóricos; inclusive, algumas vezes, sendo utilizada como expressão sinônima de tipo textual.

A partir dessa distinção, podemos compreender que os gêneros textuais se orientam por critérios externos, sócio-culturais, contextuais, comunicacionais, enquanto os tipos textuais por critérios internos, formais (estruturais e lingüísticos). Nesse sentido, os tipos e gêneros diferem por sua natureza constitutiva, a primeira, de caráter formal, e a segunda, de caráter contextual e discursivo, respectivamente.

Por sua própria natureza constitutiva, um gênero ou conjunto de gêneros não representa um referencial monolítico e imutável. Ao contrário, como representação e reflexo de contextos sóciocomunicativos e discursivos diversos, caracteriza-se pela heterogeneidade e flexibilidade de limites. A razão de podermos

\footnotetext{
${ }^{1}$ Vide Swales,1990; Adam, 1990; Bronckart, 1999; apud Marcuschi, 2005.

${ }^{2} \mathrm{O}$ tipo injuntivo incluiria as seqüências que se organizam em função de ações futuras, como ordens, pedidos, perguntas impositivas etc.
} 
estabelecer certo conjunto coerente de gêneros não se deve ao fato destes apresentarem características rígidas e bem delimitadas, mas a seu caráter recorrente em contextos mais ou menos similares de comunicação, refletindo ações sociais típicas de cada cultura. Como afirma Marcuschi (2005, p. 30), "os gêneros não são entidades naturais como as borboletas, as pedras, os rios e as estrelas, mas são artefatos culturais construídos historicamente pelos seres humanos". Desse modo, quando dominamos um gênero textual, não dominamos formas lingüísticas apenas, mas modos particulares de realizar, através da linguagem, ações sociais.

Um gênero textual, portanto, não pode ser determinado por propriedades exclusivas e imanentes. Basta-nos lançar um olhar para a infinidade de textos que nos rodeiam, orais e escritos. Um anúncio publicitário deixa de ser anúncio por ser expresso em forma de receita? E o que dizemos das cartas em forma de poema? Já os tipos textuais, são mais ou menos estáveis, mas dialogam entre si na constituição de diferentes gêneros textuais. Um artigo de opinião, por exemplo, embora apresente a tipologia de base argumentativa, pode incluir seqüências narrativas, expositivas, descritivas e injuntivas. Todos os tipos na composição de um só gênero.

Referindo-se a essa possibilidade de hibridismo, tanto dos tipos quanto dos gêneros textuais, é que Marcuschi (2005, p. 31) apresenta-nos as noções de intertextualidade inter-gêneros (um gênero com a função de outro) e a heterogeneidade tipológica (um gênero com a presença de vários tipos). No primeiro caso, evidenciamos situações em que há a fusão ou mescla de funções e formas de gêneros diversos em um dado gênero, e, no segundo, percebe-se a realização de várias seqüências tipológicas em um único gênero.

No entanto, mesmo assumindo que um gênero textual admite uma infinidade de possibilidades discursivas, além de relações intergêneros, a depender dos diferentes contextos de produção, circulação e recepção, é possível, para efeito didático-pedagógico, estabelecer um arcabouço mais ou menos coerente de tipos ou seqüências textuais e de gêneros a eles relacionados, não perdendo de vista, no entanto, que ao lidarmos com a linguagem como instância de interação humana, estamos diante do inesperado, do mesmo que pode ser outro a depender das circunstâncias e das exigências contextuais. 
Essa reflexão, no entanto, mais do que fornecer modelos acabados e organizados de como compreender a infinidade de textos e discursos que circulam à nossa volta, pode nos auxiliar a tornar mais coerentes as práticas de ensino de leitura e produção de textos, em diferentes contextos, institucionais ou não.

\section{Gêneros de textos, modos de leitura e de escrita}

A adequada compreensão do que significam os tipos e os gêneros textuais, e das diferenças que apresentam entre si, possui, a meu ver, duas vantagens teóricas, as quais se revelam em aplicações práticas. Em primeiro lugar, auxilia-nos a desfazer a confusão terminológica e conceitual que cerca essas definições e, em certa medida, as incoerências teóricas presentes nos materiais didáticos destinados ao ensino de Língua Portuguesa e nos manuais de redação, os quais insistem em desenvolver práticas de leitura e escrita baseadas na classificação tipológica tradicional, largamente difundida, representada pela narração, descrição e dissertação, sem incorporar a noção de gênero textual como instrumento de análise e valorização da capacidade humana de interagir através da linguagem. Em segundo lugar, por contribuir para orientar as ações de professores, pesquisadores e teóricos interessados em práticas pedagógicas que busquem, mais do que tudo, desenvolver a competência sócio-comunicativa, oral e escrita, dos alunos, em qualquer nível de formação escolar. Para Bakhtin (2000, p. 282):

Ignorar a natureza do enunciado e as particularidades de gênero que assinalam a variedade do discurso em qualquer área do estudo lingüístico leva ao formalismo e à abstração, desvirtua a historicidade do estudo, enfraquece o vínculo existente entre a língua e a vida. A língua penetra na vida através dos enunciados concretos que a realizam, e é também através dos enunciados concretos que a vida penetra na língua.

Textos e discursos circulam manifestados por gêneros textuais, e estes, por sua vez, incorporam marcas tipológicas que se organizam de modo heterogêneo. Os nossos alunos devem produzir textos, portanto, e não enunciados soltos. Mas o que ainda acontece, de modo geral, nas atividades de leitura e escrita que têm lugar em sala de aula é bem diferente disso. 
Os livros didáticos para o ensino de Língua Portuguesa e os manuais de redação, ou que apresentam orientações para a produção de textos, trazem uma infinidade de gêneros textuais, embora estes não sejam abordados adequadamente em suas especificidades, quando não são explorados apenas como pretexto para atividades de análise lingüística. Aspectos importantes que caracterizam a diversidade dos gêneros textuais que circulam à nossa volta, como estrutura composicional, conteúdo veiculado, estilo, situação comunicativa, tipo de suporte, entre outros, deixam de ser analisados em detrimento de aspectos superficiais da estrutura textual e de informações recuperadas na superfície do texto.

De acordo com pesquisa realizada por Bonini (1998), por exemplo, que analisou oito coleções de materiais didáticos destinados ao ensino de Língua Portuguesa no nível médio, os livros, de modo geral, voltam-se para a caracterização dos gêneros literários e, quando procuram inovar, incluindo noções de tipo textual e gênero textual, não os exploram como expressões da ação social de produzir sentidos através da linguagem, mas como formas abstratas, das quais os alunos devem "decorar" as características. Considerando-se, como tem sido amplamente discutido, o importante papel que tem o livro didático como orientador das práticas desenvolvidas em sala de aula, não é difícil prevermos as conseqüências dessas constatações para o ensino de leitura e produção de textos na escola.

Um exemplo claro disso é o fato de que os alunos que chegam ao nível superior, em sua maioria, trazem de suas experiências escolares idéias e concepções equivocadas de linguagem, de leitura e de texto, que vão determinar os modos como eles fazem uso da língua. Além disso, apresentam uma competência metagenérica, como a definem Koch e Elias (2006), pouco desenvolvida, o que os torna incapazes de compreender gêneros textuais mais complexos, como os casos em que há o processo de hibridização inter-gêneros, ou seja, a composição de gêneros diferentes na construção de um terceiro. Em minhas experiências com alunos universitários, por exemplo, percebi que eles apresentam grande dificuldade de se libertar das práticas de produção textual difundidas pela escola, as quais, via de regra, resumemse à elaboração de modelos enrijecidos de textos, cuja estrutura composicional, modo de organização do conteúdo e estilo repetemse, independentemente da especificidade do contexto de produção ou da sua função sócio-comunicativa. 
Gêneros de textos diferentes exigem processos de leitura e escrita diferentes. A partir dessa compreensão, fórmulas de leitura e modelos de escrita, como as famosas redações escolares ou as dissertações de vestibular, de nada servem, a não ser contribuir para a alienação dos alunos. É necessário, portanto, criar espaços nas instituições escolares para pactos de leitura e de escrita, tal como propõem Paulino et al. (2001), que ressaltam o fato de que cada texto estabelece um elo diferente com o leitor, e é o tipo de texto, o gênero e, por vezes, o suporte onde ele está sendo veiculado que orientam essa relação. No dizer de Eco (1994, p. 9), as relações entre leitor-texto, escritor-texto estabelecem-se como num jogo, cujas regras modificam-se através dos pactos estabelecidos entre os participantes. Para ele: "[...] todo texto é uma máquina preguiçosa pedindo ao leitor que faça uma parte do seu trabalho".

Para subvertermos práticas de ensino de língua enrijecidas e centradas na leitura e na produção de textos mecânicas e sem qualquer significado para o aluno, é preciso pensar a linguagem em uso como instância fundamental da vida, através da qual nos fazemos humanos e "dizemos" o mundo e quem somos. A partir daí, ler e escrever passam a ser ações que dialogam com nossa vivência diária e com o que pensamos do mundo. Ler e escrever um mundo todo de possibilidades, muitas entre tantos gêneros possíveis.

\section{Referências bibliográficas}

BAKHTIN, Mikhail. Marxismo e filosofia da linguagem. São Paulo: Hucitec, 2002.

A estética da criação verbal. São Paulo: Martins Fontes, 2000.

BONINI, Adair. Gêneros textuais e cognição: um estudo sobre a organização cognitiva da identidade dos textos. Florianópolis: Insular, 2002.

O ensino de tipologia textual em manuais didáticos de $2^{\circ}$ grau para a língua portuguesa. Trabalhos em Lingüística Aplicada, v. 31, p. 7-20, jan./jun. 1998. 
BRAIT, Beth. PCNs, gêneros e ensino de língua: faces discursivas da textualidade. In: ROJO, Roxane. (Org.) A prática de linguagem em sala de aula - praticando os PCNs. São Paulo: EDUC; Campinas: Mercado de Letras, 2000. p. 15-25.

ECO, Umberto. Seis passeios pelos bosques da ficção. São Paulo: Companhia das Letras, 1994.

KLEIMAN, Ângela B. Introdução. In: DIONÍSIO, Ângela Paiva; MACHADO, Anna R.; BEZERRA, Maria A. Gêneros textuais e ensino. Rio de Janeiro: Lucerna, 2005. p. 7-12.

KOCH, Ingedore V. Desvendando os segredos do texto. 4. ed. São Paulo: Cortez, 2005a.

2005b.

O texto e a construção dos sentidos. 8. ed. São Paulo: Contexto,

MARCUSCHI, Luiz Antônio. Gêneros textuais: definição e funcionalidade. In: DIONÍSIO, Ângela Paiva; MACHADO, Anna R.; BEZERRA, Maria A. Gêneros textuais e ensino. Rio de Janeiro: Lucerna, 2005. p. 19-36.

YUNES, Eliana. Dados para uma história da leitura e da escrita. In: p. $52-59$.

(Org.) Pensar a leitura: complexidade. São Paulo: Loyola, 2002. 